\title{
Evaluation of Geosynthetic-Reinforced Soil Wall Using Limit Equilibrium Analyses
}

\author{
Suliman B. A. Mohamed ${ }^{1}$, Anwar A. E. Ahmed ${ }^{2}$
}

\begin{abstract}
Current FHWA design guidelines recommend the lateral earth pressure method for designing reinforced walls (face inclinations larger than $7^{\circ}$ ) and the limit equilibrium (LE) method for designing reinforced slopes (face inclinations less than $\mathbf{7 0}^{\circ}$ ); however, this limitation is somewhat arbitrary and there is no clear reason why LE method could not be theoretically applicable to the design of reinforced walls. Therefore, this study evaluated the use of LE for predicting the failure of centrifuge geosynthetic-reinforced soil (GRS) wall models. The variables considered in the centrifuge testing program were the reinforcement types, lengths, spacing, and height of the wall models. The comparison results indicated that LE with a noncircular failure surface and centrifuge models had good agreement in locating failure surfaces. Insoil/confined ultimate tensile strengths $T_{u l t}$ of reinforcements were back-calculated from LE analyses at wall failure (FS=1.0) and consistent confined $T_{u l t}$ values were obtained for models with the same type of reinforcements. The consistent confined $T_{u l t}$ values imply that the $\mathrm{LE}$ can predict the maximum reinforcement loads at wall failure fairly well. Experimental results and the resulting discussion presented in this paper improve the understanding of $\mathrm{LE}$ analysis of geosyntheticreinforced soil walls.
\end{abstract}

Keywords-Geosynthetic-reinforced soil wall, Limit equilibrium analysis, Centrifuge model.

\section{Introduction}

Geosynthetic-reinforced soil (GRS) walls have been well accepted in practice as alternatives to conventional retaining wall systems due to several benefits such as sound performance, aesthetics, cost and expediency of construction.

Current FHWA design guidelines (Berg et al. 2009) limit the use of limit equilibrium (LE) analysis to design reinforced slopes (face inclinations less than $70^{\circ}$ ) and lateral earth pressure method to design reinforced walls (face inclinations greater than $70^{\circ}$ ). However, this limitation is somewhat arbitrary and there is no theoretical reason why the limit equilibrium method could not be extended to design reinforced walls. In authors' opinion, this limitation of face inclinations should only be applied to lateral earth pressure method but not to LE analysis. That is because the lateral earth pressure method is theoretically-based and thus limited to relatively simple geometric structures with near vertical faces and difficult to extrapolate to structures with large face inclinations and with complex geometries such as narrow walls and multi-tiered walls. Compared to the LE analysis, the lateral earth pressure method also cannot evaluate global stability directly.

Allen et al. (2003) and Bathurst et al. (2008, 2005) investigated quantitatively the accuracy of reinforcement loads predicted by the earth pressure theory using careful interpretation of a database of 30 well-monitored full-scale walls on firm foundations and reinforced fills with no positive pore water pressures. By the comparison between the reinforcement loads (estimated from measured strains) in various instrumented GRS walls and the reinforcement loads predicted using the earth pressure theory, they concluded that loads predicted using earth pressure theory were excessively conservative. The predicted loads for GRS walls were on average three times greater than estimated values for full-scale instrumented walls. Furthermore, the distribution of reinforcement loads in the instrumented walls was seen to be generally trapezoidal (or uniform) in shape rather than linear with depth as assumed in the earth pressure theory for walls with uniform reinforcement spacing. This finding contradicts the basic assumption in the earth pressure method that the soil shear strength along the failure surface mobilizes equally and reaches peak shear strength simultaneously. Overall, the use of earth pressure method is limited to relatively simple geometric structures with near vertical faces and produces safe but conservative in terms of reinforcement strength for GRS structures.

Accordingly, the objective of this study is to validate the use of LE as basis for design of GRS walls. To achieve this aim, a series of LE analyses was performed for predicting the failure of centrifuge geosynthetic-reinforced soil (GRS) wall models. Experimental results and LE predictions were compared specifically for the failure surface locations. In-soil ultimate tensile strength of reinforcement, $T_{u l t}$, back-calculated from the LE analyses at wall model failure (i.e., $\mathrm{FS}=1.0$ ), was evaluated and used to examine the LE prediction of the maximum reinforcement loads at wall failure.

${ }^{1}$ Suliman Badawi Ahmed Mohamed/ Assistant Professor Faculty of Engineering Science/ University of Nyala Sudan

\footnotetext{
${ }^{2}$ Anwar Abdalla Elamin Ahmad/ Assistant Professor Faculty of Engineering Science / University of Nyala Sudan, Northern Border University, Saudi Arabia
} 
Proc. of The Fifth Intl. Conf. On Advances in Civil and Structural Engineering - CSE 2016

Copyright (C) Institute of Research Engineers and Doctors, USA .All rights reserved.

ISBN: 978-1-63248-088-0 doi: 10.15224/ 978-1-63248-088-0-25

\section{Centrifuge Tests and Limit Equilibrium Analyses}

\section{A. Centrifuge Tests}

A series of centrifuge tests was conducted at the National Central University (NCU), Taiwan, to investigate performance and failure mechanisms in GRS walls (Hung 2008). A total of 12 centrifuge model tests were selected from the Hung's centrifuge testing program for the LE analyses in the current study. Centrifuge models were constructed in a rigid aluminum container with internal dimensions of $820 \mathrm{~mm} \times 450 \mathrm{~mm}$ in plan $\times 580 \mathrm{~mm}$ in height. Figure 1 shows a schematic profile of the model wall. All models were built on firm foundation $150 \mathrm{~mm}$ thick. The height of the reinforced wall models were varied from $120 \mathrm{~mm}$ to $300 \mathrm{~mm}$, and additional layer (equal to reinforcement spacing $S_{v}$ ) of soil was deposited on the top of the wall to cover the topmost reinforcement layer. Therefore, the wall models have an equivalent total height $H$ varied from $125 \mathrm{~mm}$ to $320 \mathrm{~mm}$, giving reinforcement spacing from $5 \mathrm{~mm}$ to $20 \mathrm{~mm}$, and number of reinforcement layers from 16 to 25 . Each reinforcement layer were folded back at the face of the wall models, forming a wrap-around facing and a secondary (overlapping) layer ( $L o=40 \%$ of reinforcement length for each wall). Table 1 summarizes the geometrical configuration, reinforcement length and spacing, and test results for the GRS wall models.

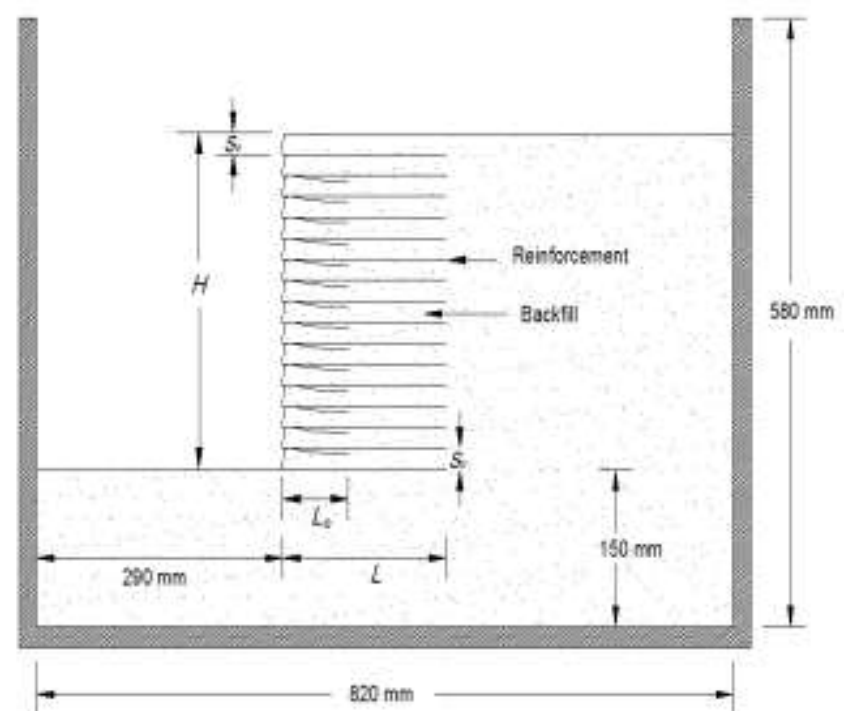

Figure 1. Schematic profile view of a centrifuge GRS wall model ( $L$ is the reinforcement length; $L_{o}$ is the overlap length of reinforcement; $S_{v}$ is Reinforcement vertical spacing)

In the centrifuge tests, all models were loaded by gradually increasing the g-level until failure. Table 1 summarizes the failure g-level, $N_{f}$, recorded for each model. Figure 2 shows the centrifuge model after wall failure observed in Test 5 . Figure 3 shows a broken reinforcement carefully retrieved from the dismantled wall models after tests completed. The nearly horizontal breakage pattern in the reinforcement validates the plane strain condition in the centrifuge tests. The location of the critical failure surface was determined based on the observed tears (ruptures) in each layer of the reinforcement. The centrifuge testing program is discussed in further detail in Hung (2008).

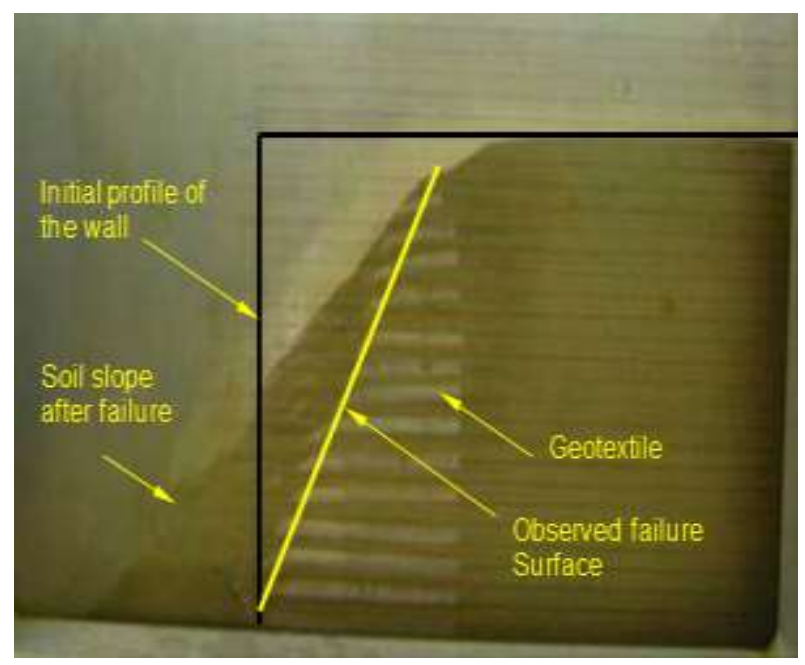

Figure 2. Photos of failure of centrifuge wall model Test 5

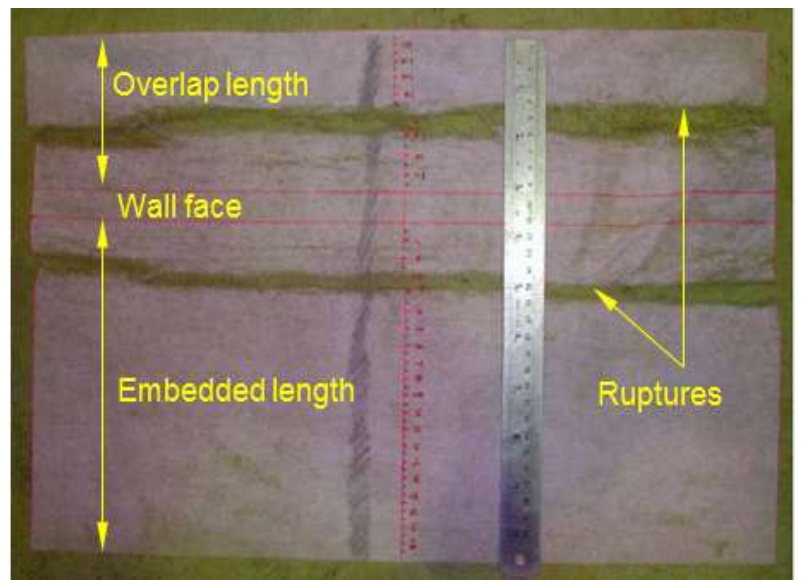

Figure 3. Breakage pattern in reinforcement material after wall failure

\section{B. Material Properties}

The soil used in the centrifuge test was clean and uniform Fulung beach sand, which is classified as poorly graded sand (SP) in the Unified Soil Classification System. The effective size $D_{10}$, uniformity coefficient $C_{\mathrm{u}}$, and coefficient of curvature $C_{\mathrm{c}}$ for the sand are $0.17 \mathrm{~mm}, 1.78$, and 1.05 , respectively. The sand was pluviated from a hopper to achieve a uniform and dense state. The backfill unit weight of sand and the friction angle obtained in a series of triaxial compression tests at the target relative density $D_{r}$ of $70 \%$ were $\gamma=15 \mathrm{kN} / \mathrm{m}^{3}$ and $\phi_{t x}=39.5^{\circ}$, respectively. To characterize the shear strength of the test sand under the plane strain condition in the centrifuge model, the plane strain peak friction angle $\left(\phi_{p s}=42.3^{\circ}\right)$ was estimated using the correlation between the triaxial compression friction angle and the plane strain friction angle ( Lade and Lee 1976):

$$
\phi_{p s}=1.5 \phi_{t x}-17
$$


Proc. of The Fifth Intl. Conf. On Advances in Civil and Structural Engineering - CSE 2016

Copyright (C) Institute of Research Engineers and Doctors, USA .All rights reserved.

ISBN: 978-1-63248-088-0 doi: 10.15224/ 978-1-63248-088-0-25

TABLE 1. Geometrical Configurations and Test Results of GRS Wall Models

\begin{tabular}{|c|c|c|c|c|c|c|c|}
\hline \multirow[b]{2}{*}{ Materials } & \multirow[b]{2}{*}{ Test No. } & \multicolumn{4}{|c|}{ Wall geometry } & \multicolumn{2}{|r|}{ Results } \\
\hline & & $\begin{array}{c}H \\
(\mathrm{~mm})\end{array}$ & $\begin{array}{c}S_{v} \\
(\mathrm{~mm})\end{array}$ & $\begin{array}{c} \\
(\mathrm{mm})\end{array}$ & $n$ & $\begin{array}{l}N_{f} \\
(\mathrm{~g})\end{array}$ & $\begin{array}{c}\text { Back-calculated } \\
T_{\text {ult }}(\mathrm{kN} / \mathrm{m}) \\
\end{array}$ \\
\hline \multirow{2}{*}{ M1 } & 1 & 250 & 10 & 170 & 25 & 35 & 0.089 \\
\hline & 2 & 125 & 5 & 85 & 25 & 120 & 0.076 \\
\hline \multirow{5}{*}{ M2 } & 3 & 320 & 20 & 210 & 16 & 34 & 0.231 \\
\hline & 4 & 288 & 18 & 190 & 16 & 45 & 0.248 \\
\hline & 5 & 256 & 16 & 168 & 16 & 56 & 0.244 \\
\hline & 6 & 224 & 14 & 147 & 16 & 64 & 0.215 \\
\hline & 7 & 192 & 12 & 125 & 16 & 85 & 0.210 \\
\hline \multirow{3}{*}{ M3 } & 8 & 320 & 20 & 210 & 16 & 58 & 0.397 \\
\hline & 9 & 288 & 18 & 190 & 16 & 72 & 0.397 \\
\hline & 10 & 256 & 16 & 168 & 16 & 90 & 0.391 \\
\hline \multirow{2}{*}{ M4 } & 11 & 320 & 20 & 210 & 16 & 65 & 0.444 \\
\hline & 12 & 250 & 15 & 140 & 16 & 95 & 0.420 \\
\hline
\end{tabular}

Note: M1 = Wood pulp fabric; M2 = Rayon fabric; M3 = Polyester, rayon fabric; M4 = Polypropylene fabric $H=$ Height of wall model; $S_{v}=$ Reinforcement vertical spacing; $L=$ Length of model reinforcement; $n=$ Number of reinforcement layers ; $N_{f}=$ Failure g-level of centrifuge model; $T_{u l t}=$ Back-calculated ultimate tensile strength of reinforcement

The geotextiles used in the centrifuge study were nonwoven wood pulp, rayon, polyester rayon, and polypropylene fabric, referred to as M1, M2, M3, and M4, respectively. A series of unconfined wide-width tensile tests (ASTM D4595) and zero-span tests with clamps $6 \mathrm{~mm}$ apart (Porbaha and Goodings 1996) were performed to evaluate the tensile strength properties of the geotextile materials. Table 2 summarizes the main reinforcement characteristics of the four different geotextile materials. The average $T_{u l t}$ for the geotextiles M1, M2, M3, and M4 were $0.06,0.11,0.17$, $0.25 \mathrm{kN} / \mathrm{m}$ from wide-width tests and $0.1,0.24,0.37$, and $0.40 \mathrm{kN} / \mathrm{m}$ from zero-span test, respectively. As the nonwoven geotextile tensile strengths were found to be affected by soil confinement and impregnation of geotextile by soil particles (Boyle et al. 1996), unconfined tensile tests like wide-with and zero-span tensile tests may not accurately represent in-soil tensile strength values. However, experimentally quantifying the in-soil mechanical properties of low strength nonwoven fabrics is difficult. This study therefore performed a back analysis to calculate the insoil/confined ultimate tensile strengths $T_{u l t}$ of reinforcements. Figure 4 and Table 2 show the average back-calculated confined $T_{u l t}$ values. The back analyses used to obtain the values for confined $T_{u l t}$ and a comparison of the confined and unconfined $T_{u l t}$ values are discussed further in next sections.

\section{Limit equilibrium analyses}

Limit equilibrium analyses are typically used to analyze the stability of natural and reinforced slopes. A series of centrifuge tests of GRS slopes by Zornberg et al. (1998) showed that LE is effective for predicting failure in GRS slopes. In the current study, LE analyses were performed to predict the locations of failure surfaces in GRS wall models and to assess the confined ultimate tensile strength of reinforcements. The LE calculations were performed using
Spencer's method with circular and noncircular critical failure surfaces as coded in the Slide v.6.0 program. The Spencer's method, which is sufficiently rigorous to satisfy all equilibrium conditions, assumes that all inter slice forces are parallel. The shear strength of the test sand in the centrifuge model was characterized by the plane strain friction angle. Centrifugal force was simulated by increasing the unit weight of backfill $N_{f}$ times until it corresponded to the target g-level at failure. The critical failure surface was identified to initiate from the toe of the wall model.

The LE analyses in this study assumed a uniform distribution of reinforcement tensile forces with depth (Fig. 5), horizontal orientation of reinforcement forces, and overlapping geotextile layers modeled as additional reinforcements that increased stability in the wall. The tensile strength of reinforcement used as input in LE analysis was adjusted until a factor of safety was reached FS $=1.0$ in each centrifuge test model. The estimate accounted for the back-calculated confined ultimate tensile strength of the reinforcement and was expected to equal the average insoil reinforcement tension at the moment of failure. Finally, reduction factors such as creep, installation damage and degradation were excluded because the centrifuge model tests were meticulously constructed to ensure that no installation damage occurred. The test duration was also kept sufficiently short to avoid long-term behavior such as creep or degradation.

\section{Results and Discussions}

\section{A. Location of Failure Surface}

Figure 6 compares the locations of failure surfaces obtained experimentally from centrifuge tests and the locations of critical failure surfaces predicted by LE analyses. 
Proc. of The Fifth Intl. Conf. On Advances in Civil and Structural Engineering - CSE 2016

Copyright (C) Institute of Research Engineers and Doctors, USA .All rights reserved.

ISBN: 978-1-63248-088-0 doi: 10.15224/ 978-1-63248-088-0-25

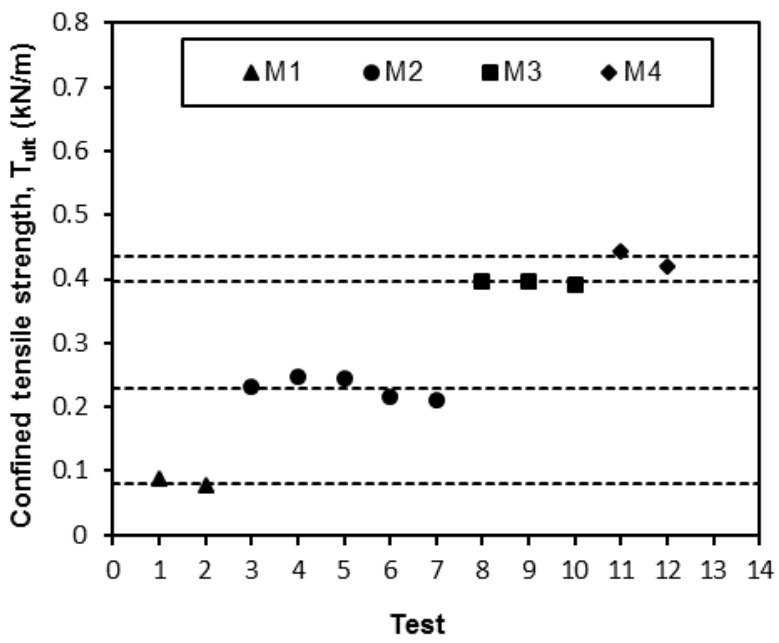

Figure 4. Back-calculated ultimate confined tensile strengths of the reinforcements

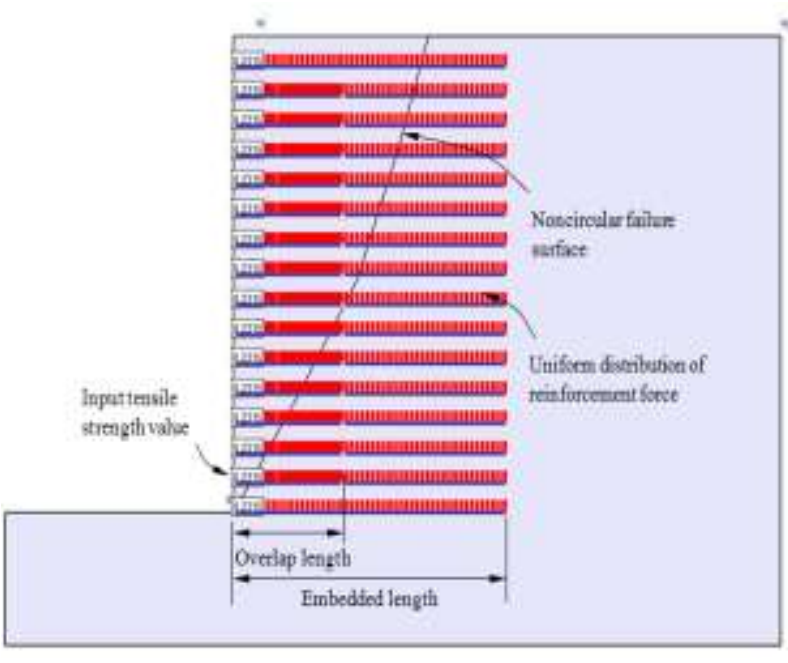

Figure 5. Reinforcement force distribution and failure surface used in LE analyses

TABLE 2. Geotextile Properties Used as Reinforcement in Model Tests

\begin{tabular}{|c|c|c|c|c|c|}
\hline \multirow{2}{*}{ No. } & \multirow{2}{*}{ Materials } & \multirow{2}{*}{$\begin{array}{l}\text { Thickness } \\
\text { (mm) }\end{array}$} & \multicolumn{3}{|c|}{$\begin{array}{c}\text { Ultimate tensile strength } \\
T_{u l t}(\mathrm{kN} / \mathrm{m})\end{array}$} \\
\hline & & & Wide-width Test & $\begin{array}{c}\text { Zero-span } \\
\text { Test }\end{array}$ & $\begin{array}{c}\text { Average back- } \\
\text { calculated }\end{array}$ \\
\hline M1 & Wood pulp & 0.07 & 0.06 & 0.1 & 0.083 \\
\hline M2 & Rayon & 0.13 & 0.11 & 0.24 & 0.230 \\
\hline M3 & Polyester, Rayon & 0.15 & 0.17 & 0.37 & 0.395 \\
\hline M4 & Polypropylene & 0.13 & 0.25 & 0.40 & 0.432 \\
\hline
\end{tabular}

The failure surface of the centrifuge wall model, black triangles in Fig. 6, was identified by the tears (ruptures) observed in each reinforcement layer. The failure surface in LE analysis was identified by searching for both circular and noncircular critical surfaces. In Fig. 6, comparison results indicate a very good agreement between the critical noncircular failure surfaces predicted by the LE analyses and those actually observed in the experiments. Notably, the predicted critical circular failure surfaces slightly differ from the actual failure surfaces, in particular near the top of the wall. Figure 6 also shows comparison between experimental failure surfaces and the theoretical Rankine failure surfaces $\left(45+\phi_{\mathrm{tx}} / 2\right)$ recommended by FHWA design guidelines for a given triaxial compression friction angle of backfill. In most cases, the comparison results show that the theoretical Rankine failure surface can depict the locations of failure surfaces well, expect for Test 11 as shown in Fig. 6(d).

Overall, it can be concluded that the LE approach with a noncircular failure surface is competent of accurately predicting the failure surfaces in GRS wall models. Comparison results also support modeling assumptions (e.g., use of the noncircular failure surface, uniform distribution of reinforcement forces with depth, and horizontal orientation of reinforcement forces). Finally, in design of GRS structures, reinforcement length that extends beyond the failure surface provides sufficient pullout resistance. Therefore, accurate identification of failure surface location by LE analysis confirms that it is effective for evaluating whether the internal stability of these structures is sufficient to withstand reinforcement pullout.

\section{B. In-Soil Geotextile Tensile Strength}

Ultimate tensile strength of reinforcement is the most important parameter when designing reinforced structures that resist reinforcement rupture. As mentioned, the ultimate tensile strength measured in the centrifuge test may differ from that measured in the standard unconfined tensile test due to soil confinement and impregnation of the geotextile by soil particles. One alternative is to evaluate in-soil geotextile strength by back-calculation from the centrifuge model results at failure.

Figure 4 and Table 2 show the calculated $T_{u l t}$ values which account for the average in-soil reinforcement tension at failure. As can be seen in Fig. 4, consistent confined $T_{u l t}$ values were obtained for models with the same type of the reinforcement. The consistent confined $T_{u l t}$ values are considered rational because the $T_{u l t}$ for the same type of reinforcement is expected to be similar, which also implies that the LE can predict the maximum reinforcement loads at wall failure fairly well. In addition, as shown in Table 2 , the average confined $T_{u l t}$ values for all the reinforcements are larger than those obtained from the wide-width test and close to those obtained from the zero-span test. The reason of the confined $T_{u l t}$ values close to those from zero-span test is because the in-soil confinement of geotextiles restrains geotextile deformations in the direction perpendicular to loading which is similar to effect of preventing the geotextile necking in the zero-span test. These analytical results are consistent with previous studies (Christopher et al. 1986; Zornberg et al. 1998) demonstrated that the likely range for the in-soil tensile strength value of nonwoven geotextile can be defined using wide-width and zero-span tensile tests. 


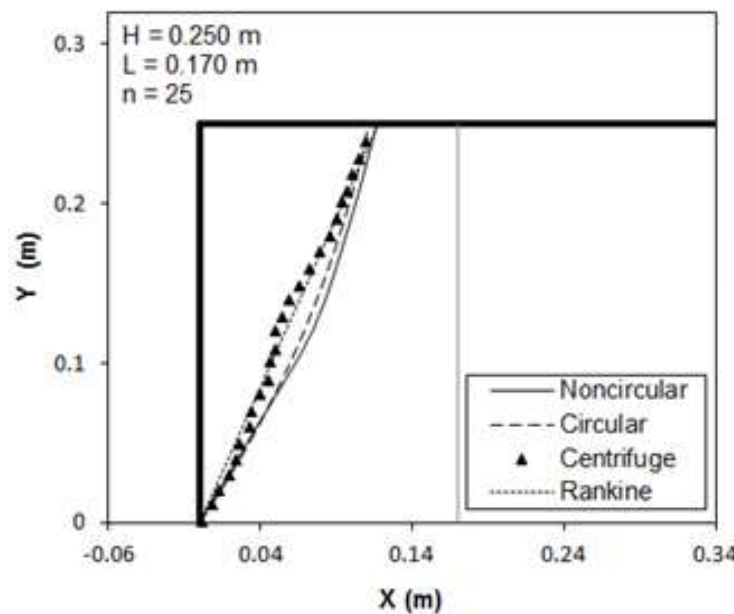

(a)

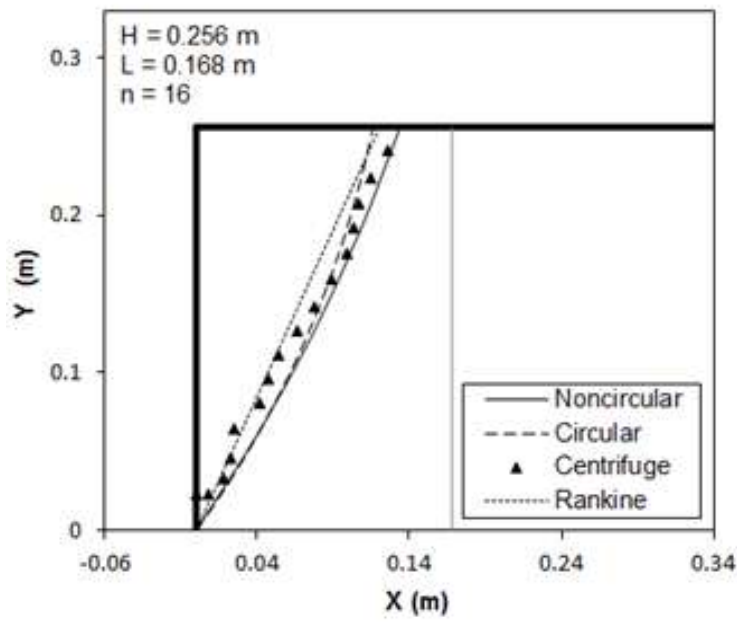

(c)



(b)

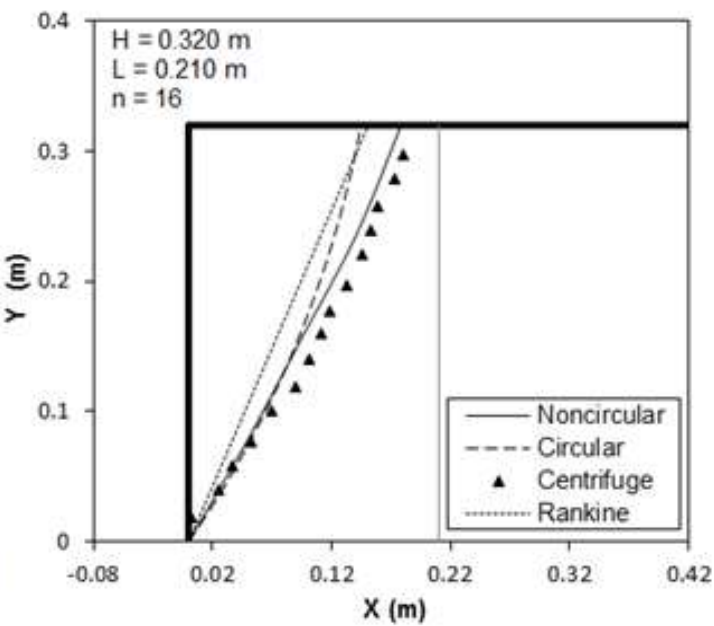

(d)

Figure 6. Predicted and measured locations of failure surfaces from centrifuge tests: (a) Test 1 (M1); (b) Test 5 (M2); (c) Test 10 (M3); (d) Test 11 (M4)

\section{Conclusions}

This study conducted a series of LE analyses for centrifuge modeling of GRS walls with various reinforcement types and layouts and wall heights. This study demonstrated that LE can predict the failure (i.e., location of failure surface and the confined ultimate tensile strength) of centrifuge geosynthetic-reinforced soil (GRS) wall models well. Specific conclusions drawn from this study are summarized below:

- The location of the critical noncircular failure surface predicted by LE analysis agrees well with the actual location of the critical failure surface obtained experimentally, which implies that the LE is capable of evaluating the required reinforcement length against pullout.

- Consistent confined $T_{u l t}$ values were obtained for models with the same type of the reinforcement, which implies that the LE can predict the maximum reinforcement loads at wall failure fairly well. The average confined $T_{u l t}$ values for all the reinforcements are larger than those obtained from the zero-span test.

\section{Acknowledgment}

The financial support for the first author during his study in Taiwan and the research funding for the centrifuge model tests conducted by the Hung are gratefully acknowledged. The authors also sincerely appreciate the constructive comments by the anonymous reviewers.

\section{References}

[1] Allen, T.M., Bathurst, R.J., Holtz, R.D., Walters, D., and Lee, W.F., “ A new working stress method for prediction of reinforcement loads in geosynthetic walls," Canadian Geotechnical Journal, Vol. 40, No. 5, pp. 976-994, 2003.

[2] ASTM D4595, "Standard test method for tensile properties of geotextiles by the wide-width strip method," American Society for Testing and Materials. West Conshohocken, PA, USA.

[3] Bathurst, R.J., Miyata, Y., Nernheim, A., and Allen, T.M, “ Refinement of K-stiffness method for geosynthetic reinforced soil walls" Geosynthetics International, Vol. 15, No. 4, pp. 269-295, 2008.

[4] Bathurst, R. J., Allen, T. M., and Walters, D. L., " Reinforcement loads in geosynthetic walls and the case for a new working stress 
design method," Geotextiles and Geomembranes, Vol. 23, No.4, pp. 287-322, 2005.

[5] Berg, R., Christopher, B. R., and Samtani, N., “ Design of mechanically stabilized earth walls and reinforced soil slopes," Vol. I and II. Report No. FHWA-NHI-10-024, Federal Highway Administration, 2009.

[6] Boyle, S. R., Gallagher, M., and Holtz, R. D., “ Influence of strain sate, specimen length and confinement in measured geotextile properties," Geosynthetics International, Vol. 3, No. 2, pp. 205-225, 1996.

[7] Christopher, B.R., Holtz, R.D., and Bell, W.D., “ New tests for determining the in-soil stress-strain properties of geotextiles," Proceedings of the Third International Conference on Geotextile, Vienna, Austria, Vol. 3, pp. 683-686, 1986.

[8] Hung, W.Y., "Breaking failure behavior and internal stability analysis of geosynthetic reinforced earth walls," Ph. D. Dissertation, National Central University, Jhongli, Taiwan, 2008.

[9] Lade, P.V., and Lee, K.L., "Engineering properties of soils," Report UCLA-ENG-7652, University of California, Los Angeles, Calif, 1976.

[10] Porbaha, A. and Goodings, D. J., "Centrifuge modeling of geotextile reinforced cohesive soil retaining walls," Journal of Geotechnical Engineering, ASCE, Vol. 122, No. 10, pp. 840-848, 1996.

[11] Zornberg, J. G., Sitar, N., and Mitchell, J. K., "Limit equilibrium as basis for design of geosynthetic reinforced slopes," Journal of Geotechnical and Geoenvironmental Engineering, ASCE, Vol. 124, No. 8, pp. 684-698, 1998.

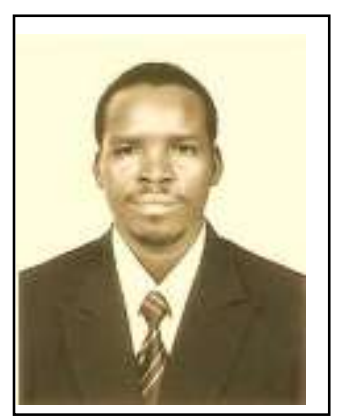

\section{Suliman Badawi Ahmed Mohamed Assistant Professor Department of Civil Engineering, University of Nyala, Sudan}

Phone: +249964152583

He completed his Ph.D. degree at the National Taiwan University of Science and Technology (Taiwan Tech) in 2014 under the supervision of Professor Kuo-Hsin Yang. He received his Master degree from the Institute Technology Sepuluh Nopember (ITS), Indonesia in 2010 with High Honors, and Bachelor of Science degree from the University of Nyala, Sudan in 2005. Dr. Mohamed has experiences in research and practice in geotechnical and geosynthetics engineering. To date, Dr. Mohamed has published 3 technical articles in journals, 4 papers in conferences and 3 reports.

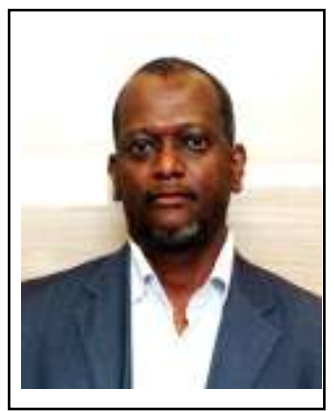

\section{Anwar Abdalla Elamin Ahmad Assistant Professor \\ Department of Civil Engineering, University of Nyala, Sudan \& Northern Border University, Saudi Arabia}

He completed his Ph.D. degree at University of Khartoum, Sudan, in 2011. He received his Master degree from the Karay University, 2005, and Bachelor of Science degree from the Red Sea University, Sudan in 2000. Dr. Ahmed has experiences in research and practice in Structural Engineering. To date, Dr. Ahmed has published one technical articles in journals, one papers in conferences and 3 reports. 